\title{
Mental Health and Well-Being of Solid Organ Transplant Donors. The Forgotten Sacrifices
}

\author{
Xin-Hui Pan ${ }^{1,+}$, Jonathan Zhi Kai Toh ${ }^{1,+}$, Cheng Han $\mathrm{Ng}^{1, * \mathbb{D}}$, Phoebe Wen Lin Tay ${ }^{1}$, Neng Wei Wong ${ }^{2}$, \\ Alfred Wei Chieh Kow 1,3,4, Anantharaman Vathsala 1,5, Eunice Xiang-Xuan Tan 1,4, Mark Dhinesh Muthiah 1,4 ${ }^{1}$ \\ and Wen Hui Lim 1,*
}

Citation: Pan, X.-H.; Toh, J.Z.K.; Ng, C.H.; Tay, P.W.L.; Wong, N.W.; Kow, A.W.C.; Vathsala, A.; Tan, E.X.-X.; Muthiah, M.D.; Lim, W.H. Mental Health and Well-Being of Solid Organ Transplant Donors. The Forgotten Sacrifices. Transplantology 2021, 2 , 274-287. https://doi.org/10.3390/ transplantology2030026

Academic Editors: Luis Pintor, Anna Lligoña, Hugo Lopez-Pelayo and Wisit Cheungpasitporn

Received: 23 May 2021

Accepted: 9 July 2021

Published: 19 July 2021

Publisher's Note: MDPI stays neutra with regard to jurisdictional claims in published maps and institutional affiliations.

Copyright: (c) 2021 by the authors Licensee MDPI, Basel, Switzerland. This article is an open access article distributed under the terms and conditions of the Creative Commons Attribution (CC BY) license (https:// creativecommons.org/licenses/by/ $4.0 /)$.
1 National University Centre for Organ Transplantation, National University Health System, Singapore 119074, Singapore; e0421828@u.nus.edu (X.-H.P.); e0421782@u.nus.edu (J.Z.K.T.); e0421869@u.nus.edu (P.W.L.T.); alfred_kow@nuhs.edu.sg (A.W.C.K.); anantharaman_vathsala@nuhs.edu.sg (A.V.); eunice_xx_tan@nuhs.edu.sg (E.X.-X.T.); mark_muthiah@nuhs.edu.sg (M.D.M.)

2 Department of General Surgery, National University Health System, Singapore 119074, Singapore; neng_wei_wong@nuhs.edu.sg

3 Division of Hepatobiliary \& Pancreatic Surgery, Department of Surgery, National University Hospital, Singapore 119074, Singapore

4 Division of Gastroenterology and Hepatology, Department of Medicine, National University Hospital, Singapore 119074, Singapore

5 Division of Nephrology, University Medicine Cluster, National University Hospital, Singapore 119074, Singapore

* Correspondence: chenhanng@gmail.com (C.H.N.); e0421795@u.nus.edu (W.H.L.); Tel.: +65-6772-3737 (C.H.N.)

+ Equal contribution.

Abstract: In light of a global organ shortage, living donor transplantation has become increasingly relevant as an alternative to deceased donor transplantation. While current research has revolved around the medical aspects of transplantation, there remains a paucity of literature regarding the quality of life (QOL) of living donors. Hence, this review aims to provide a comprehensive outline of the current landscape of living liver and kidney transplantation, with a focus on the mental health and wellbeing of donors. As highlighted in previous studies, organ donation has a significant impact on both physical and mental aspects of donor wellbeing, with marked deteriorations occurring in the short term. Furthermore, other qualitative aspects such as financial burden contribute greatly to donor distress, reflecting a need for improved donor care. To address these pertinent issues, recommendations for a successful transplant program are detailed in this review, which encompasses psychological and social aspects of donor care throughout the donation process. Further research can be done on the impact of recipient deaths on donor QOL and appropriate interventions. Overall, given the selfless sacrifices of living donors, the care of their mental wellbeing is essential. Therefore, greater emphasis should be placed on the provision of adequate psychosocial support for them.

Keywords: living donors; mental health; quality of life; liver transplantation; kidney transplantation; patient care; program development; aftercare; psychosocial intervention; counseling

\section{Introduction}

There is no organ without a donor. Since the first living donor kidney transplant (LDKT) in 1954 [1] and first living donor liver transplant (LDLT) in 1988 [2], the global prevalence of living donor transplants has increased rapidly, especially in Asia. Based on the 2015 annual report from the Global Observatory on Donation and Transplantation (GODT), 84,347 kidney transplants were performed with $41.8 \%$ from living donors while 27,759 liver transplants were performed with $21.0 \%$ from living donors [3]. While deceased donors have been the traditional source of organs in transplant in the West, the current 
supply of deceased donor organs for transplant remains insufficient to meet the rising demand [4]. Current estimates suggest that up to 16,000 patients remain on the waiting list for liver transplants while only 6000 transplants are performed annually in the United States (US) [5]. In contrast to the West, living donor transplants remain the prevalent source of donor organs in Asia due to the lack of deceased organ donations. Cultural perspectives and societal values remain the main hurdles for deceased donor transplantation: e.g., the requirement for completeness of the body during funeral rites [6]. At present, LDLT constitutes more than $90.0 \%$ of total liver transplants in Asia [5] and more than $50.0 \%$ of kidney transplants are from living donors across the Philippines, Japan, South Korea, Singapore and Thailand [7].

\section{Methods}

The design of this study is a narrative review and detailed searches for relevant citations were conducted on PubMed and Google Scholar from inception to May 2021 using keywords including "donor", "well-being", "mental health", and "quality of life" as well as related synonyms. In addition, references of included articles were screened to obtain any other relevant sources. The inclusion criteria were liver or kidney transplantation and living donor wellbeing. The scope of the review covers quality of life of adult living donors after liver or kidney transplantation with a comprehensive outline of elements of a successful wellbeing program targeted at this population.

\section{Current Status of Living Donor Transplant}

Over the last decade, living donor transplantation has become increasingly relevant as an alternative to deceased donor transplantation. In contrast to deceased donor organs, living donor organs are not restricted by donor mortality, allowing increased organ availability [8], transplantation to be performed on an elective basis and reducing waiting list mortality among transplant candidates [8,9]. In addition, LDLT allows for transplantation at a lower model for end-stage liver disease (MELD) score, shorter intensive care unit stay and consequently better post-transplant outcomes [10]. Similarly, increased graft and patient survival rates have been observed in LDKT as compared to deceased donor kidney transplantation (DDKT) [11]. LDLT has been postulated to confer immunological advantages over deceased donor liver transplantation (DDLT) due to a reduction in inflammation and ischemia time, as well as genetic similarities with biologically related donors [12]. Evident in reduced rates of acute cellular rejection among LDLT recipients, this may suggest increased tolerance although the long-term outcomes after immunosuppression withdrawal are not well elucidated [13].

Despite the benefits of living donor transplantation over deceased donor transplantation, the former is not without its risks and is still a big undertaking for the donor who is otherwise healthy. Mortality of LDLT is $0.1-1 \%$ while that of LDKT is less than $0.03 \%[14,15]$. To compound this further, practical considerations relating to implications on subsequent insurance coverage further creates undue stress that may deter potential donors [16].

The Living Donor Protection Act (LDPA) was recently introduced in the US to increase living donation rates [17]. Current estimates suggest a gradual upward trend for living donation in the US which peaked at 6867 LDKTs [18] and 524 LDLTs [19] in 2019. However, these donations still account for only a small proportion of total annual transplants [20]. Based on 2020 Organ Procurement Transplantation Network (OPTN) data, LDLT constitutes only $5.1 \%$ of annual liver transplantations in the US and only $30.5 \%$ of kidney transplants were from living donors [21]. Under the LDPA, insurance companies are prohibited from withholding insurance or practising discriminatory pricing against living organ donors [17]. This potentially addresses a crucial legislative gap in increasing the donor pool which will translate into decreased waitlist length and improved donor-recipient match rates. 


\section{The Impact of Organ Donation on Donors}

While organ donors are investigated thoroughly to reduce post-operative complication as far as possible, there are still significant risks even to healthy donors. Infection is the most common post-operative complication affecting living donors [22,23], and 6.6\% of LDLT donors were found to develop biliary complications such as bile leaks and strictures [14]. Moreover, it has been reported that up to $21.0 \%$ of donors complain of fatigue and pain [24], with marked deteriorations in physical quality of life (QOL) documented at three months [25-27]. Besides the inherently high risk of medical complications, the psychological strain accompanying living transplantation poses significant threats to donor wellbeing most significant at three months post-donation [25,28]. A total of $4.7-9.6 \%$ of donors suffer diminished mental QOL after transplant [28], which can often be exacerbated by recipient death, anxiety regarding recovery, insufficient medical care and financial difficulties with insurance claims $[29,30]$.

In particular, recipient deaths can have devastating effects on donors' psychological wellbeing [26] with large decrements in mental health and vitality aspects of QOL scores [31]. In addition, a substantial increase in depression risk of $123 \%$ was reported among unrelated donors whose recipients died [32], of which $8 \%$ developed suicidal ideations [33]. The rapid psychological decline in donors could be attributed to guilt and feelings of responsibility [28]. Furthermore, the deceased recipients' families are less likely to treat donors with greater respect or gratitude during the grieving process [34], adding to the mental and emotional burden carried by donors.

\section{Current Guidance on Donor Wellbeing}

With increasing recognition of living donor well-being, several transplant societies have crafted recommendations on pre-donation assessment, surgical and post-donation care plans for living donors (Figure 1). The majority of the clinical guidelines recommend pre-transplant psychosocial assessment of potential donors to ensure psychological fitness and prevent coercion [35-40]. Similarly, most societies emphasize the importance of integrating donors into transplant care teams which serve as supportive networks [37,38,41]. Another key recommendation is to improve communication of physicians during pretransplant workup to help donors set realistic expectations of graft success rates and make informed decisions $[36,42,43]$. Some guidelines further suggest for donors to be paired with advocate(s) who will promote their best interests $[35,36,43]$ while others encourage financial counselling [35,36,38].

In terms of post-transplantation care, all guidelines encourage transplant centres to monitor donors' physical and psychological wellbeing [35-38,42]. Only the OPTN provided additional recommendations to monitor socioeconomic concerns of donor, who may face loss of income due to time needed to recover from their organ donations $[34,35]$. Other possible gaps in donor care include lack of recommendations on post-transplant physical rehabilitation which has been shown to aid in reconditioning while reducing fatigue [44,45], as well as insufficient psychological provisions for potential candidates who fail to donate due to clinical reasons or personal preferences. Lastly, there remains room for improvement to advocate for lifelong follow-up of donors, with most practices implementing two years follow-up duration $[35,36]$ despite studies suggesting key complications arising many years post-transplant [35]. 


\section{Summary of Existing Guidelines on Donor's Wellbeing}

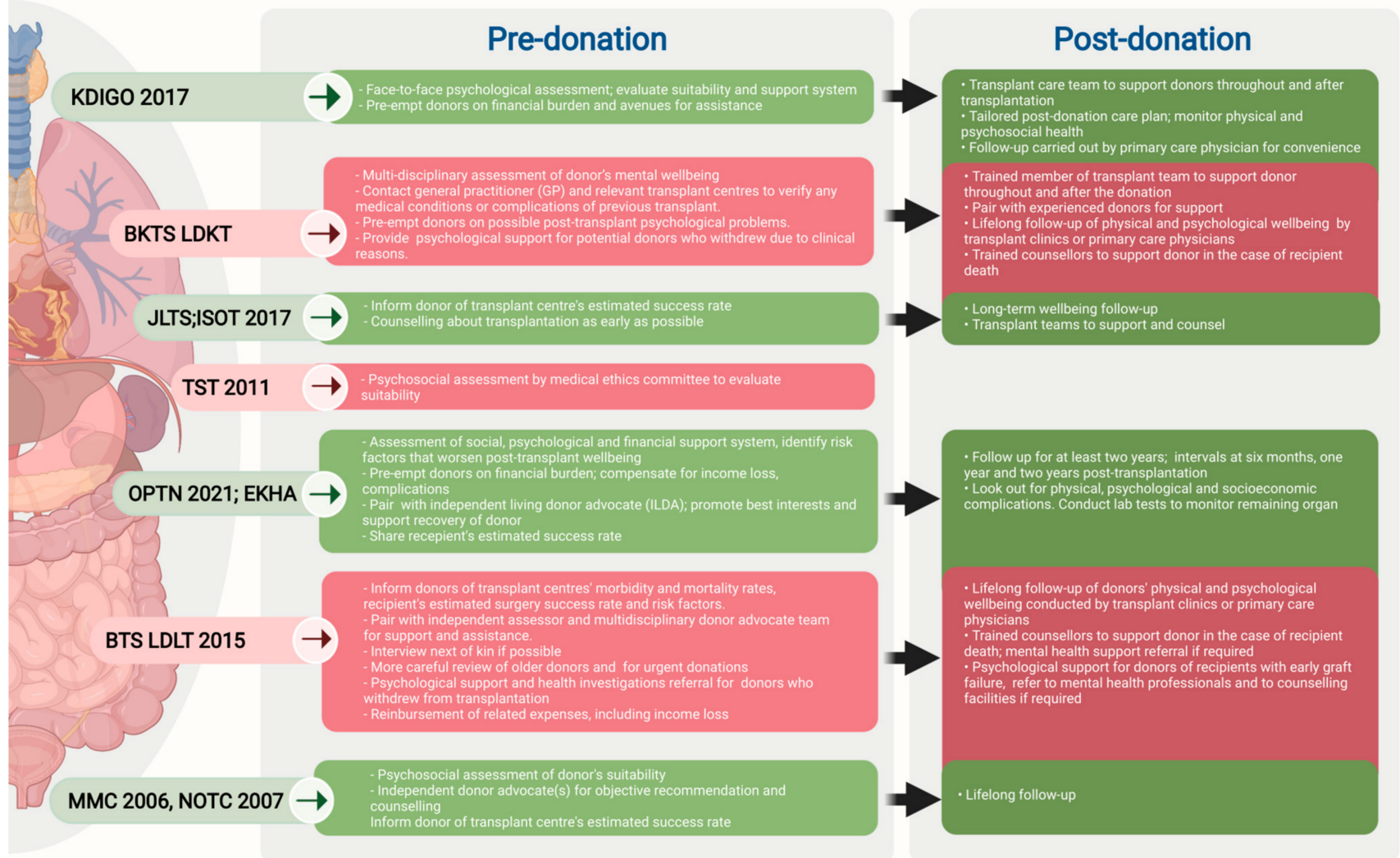

Figure 1. Summary of Existing Guidelines on Donor's Wellbeing.

\section{Risk Factors for Adverse Mental Outcomes in Donors}

At present, the two largest scale studies involving LDLT are the Adult-to-Adult Living Donor Liver Transplantation Cohort Studies, A2ALL [26] from 1998 to $2003(n=819)$ [46] and A2ALL-2 [28] from 2011 to $2014(n=1871)$ [47], involving nine transplant centres in North America. In the A2ALL consortium, 374 patients were monitored for up to 11 years using the short-form health surveys (SF-36) which revealed that health-related quality of life (HRQOL) for most living donors were not significantly affected by LDLT [26]. The only predictive variables for lowered physical and mental component scores were recipient death and lower educational attainment of donors. Likewise, the A2ALL-2 study demonstrated low rates of psychiatric episodes and higher self-esteem post-donation that continued over time, with $95 \%$ out of 271 donors reporting willingness to donate again. Both studies highlighted the low rates of physical and psychological complications in donors, but revealed greater need for psychological support in potentially vulnerable groups, such as bereavement counselling for donors whose recipients died [28] and predonation education and targeted post-donation care for donors with low educational attainment [26].

The Kidney Donor Outcomes Cohort (KDOC) study is a prospective study from 2011 to 2018 involving six transplant centres across the US, with 193 LDKT donors and 20 control subjects [48]. In contrast to LDLT donors, this study found that $16 \%$ of LDKT donors developed new onset anxiety, depression and anger, while $21 \%$ had increased worry about kidney injury or failure at one or more post-donation assessments up to two years. A significant proportion of LDKT donors (10\%) developed low life satisfaction although 96\% reported no regrets donating their kidneys at two years [48]. However, long term QOL assessment remains lacking, despite the fact that most non-surgical LDKT complications such as hypertension and diabetes only surface five years post-donation [49]. Therefore, 
more prospective studies on longer term psychological effects of LDLT and LDKT donors are warranted.

\section{Elements of a Successful Wellbeing Programme}

\subsection{Pre-Donation}

Education. During decision making, many donors face issues recalling the vast amount of information shared [50] and thereby suffer mental fatigue [51]. A possible solution can be adapted from the tailored computer education intervention for LDKT recipients, "Your Path to Transplant", where recipients receive personalised education according to their existing transplant knowledge and are involved in discussions to address their fears, barriers and readiness for transplantation [51]. Drawing inspiration from the success of this program, the implementation of a similar programme for both liver and kidney donors can help improve their understanding of the transplant process [52]. This prepares potential donors mentally, emotionally and financially [52], and empowers them to make better informed decisions, thus reducing post-transplant anxiety and distress. Importantly, pre-donation education and post-donation care should be better targeted at donors of varying socioeconomic groups and health literacy levels [26], considering that donors with low educational attainment tend to fare more poorly physically and psychologically [26]. For instance, existing materials on living donation are often pitched at freshman college reading level [53], however considerations should be made to adapt educational materials for individuals with lower health literacy [53] to protect their right to a robust transplant education and ensure the mental wellbeing of this vulnerable population.

Motivational interviewing (MI). Residual ambivalence, defined as lingering hesitancy after a donors' agreement to donate [54], is often associated with poorer physical and psychological outcomes for donors [55]. Assessed using the seven-items Simmons ambivalence scale, ambivalence is observed in approximately $75 \%$ of donors before donation [54]. To reduce the adverse consequences of ambivalence, potential donors can be referred for MI which encourages candidates to verbalise their intentions for donation and make decisions that are aligned to their values [54]. By resolving ambivalence, donors will feel more committed and hence more in control of their decision [55]. Dew et al. noted that following MI, donors had fewer physical complications, less anxiety and were also able to recover more quickly post-donation [54].

Standardised psychosocial assessment tools. Currently, there are no psychological assessment tools that can be incorporated across all clinical guidelines [33]. Standardised psychosocial assessment tools should be established to streamline the assessment process and standardise the eligibility criteria for donors. For instance, the multidimensional ethical, legal, and psychosocial aspects of transplantation (ELPAT), living organ donor psychological assessment tool (EPAT) [33], and the nine-domains liver donor assessment tool (LDAT) [33] aim to cover multiple aspects of potential donors' wellbeing to attain a holistic understanding of their psychosocial health. This allows the quantification of psychosocial risks beyond the standard low, moderate or high-risk classifications [33], facilitating better communication of risk profile of donors between transplant teams. Furthermore, with multi-dimensional assessments, areas where potential donors fare more poorly can be identified for early initiation of interventions to support candidacy [33].

Socioeconomic evaluation. Socioeconomic evaluation is an essential component of pre-transplant evaluation [35] due to the significant financial burden faced by donors [34] coupled with difficulties obtaining insurance [16]. There is a positive correlation between financial burden faced by donors and an increased risk of depression [56]. Therefore, counselling services by an integrated care team including a social worker should be provided to discuss appropriate support schemes, emphasizing the need for interprofessional collaboration and integration in promoting holistic patient-centred support [57]. 


\subsection{Post-Donation}

Follow-up. Post-transplantation programs should include lifelong medical followup of donors [36,37], facilitated by a donor registry which records donor complications and mortality [58]. During follow-up visits, donor screening should cover physical and mental aspects of health [38] as well as socioeconomic evaluation [35], allowing appropriate interventions to be implemented to maximise donor QOL.

Physical rehabilitation. Close monitoring of common physical symptoms such as fatigue and pain [24] are essential to preserve donor wellbeing, as prolonged recovery to baseline and frequent hospital visits are associated with poor HRQOL [59]. Deleterious effects of fatigue on psychological wellbeing are evident in increased likelihood of depressive symptoms and sleep disorders [60]. Similarly, poorly managed pain is known to have detrimental impacts on psychological outcomes [61], such as a two-fold increase in the risk of suicide mortality among individuals suffering from chronic pain [62]. In order to mitigate these risks among donors, physical screening should be conducted using the functional assessment of chronic illness therapy-fatigue subscale (FACIT-F), brief pain inventory (BPI) or physical component score (PCS) of the SF-36 [24], followed by physiotherapy which aids with fatigue [44], respiratory muscle tone [63] and immune function [45]. For pain management, epidural (levobupivacaine) or intravenous (morphine) analgesia may be used at controlled doses for acute pain during post-operative stay while pregabalin may be used to alleviate chronic pain [64]. Long-term pain management for donors further necessitates close collaboration between the anaesthesiologist and pharmacist for therapeutic drug monitoring. In addition, transplant centres may employ enhanced recovery after surgery (ERAS) interventions [65], a multidisciplinary and patient-centred approach including patient education, behavioural changes, diet modification and conservative treatment, to expedite donors' recovery process which promotes the physical and mental health of donors.

Psychological interventions. Psychological assessment of donors should include screenings for insomnia, depression, and anxiety which may arise from poor recipient outcomes [45] or socioeconomic stressors [66]. To facilitate psychiatric evaluation, the mental component score (MCS) of the SF-36 [67], the patient health questionnaire (PHQ-9) depression scale [68], the seven-item general anxiety disorder (GAD-7) scale [69] and the Pittsburgh sleep quality index (PSQI) [70] may be utilized. Post-screening, donors found to have depression may be followed up with cognitive behavioural therapy (CBT), acceptance and commitment therapy (ACT) or mindfulness-based cognitive therapy (MBCT). Based on the hypothesis that mental disorders are attributed to defective patterns of thought [71], CBT involves patients in collaborative problem-solving with their therapists to dispute such thought patterns, thereby reducing symptomatic depression and anxiety [72]. A recent meta-analysis conducted by Foroushani et al. found that CBT conducted via computer platforms remain highly effective in treating depression [73]. Therefore, CBT may be administered virtually to living donors, potentially reducing inconvenience associated with repeated visits. In contrast to $\mathrm{CBT}, \mathrm{ACT}$ and $\mathrm{MBCT}$ focus on improving patient relationship to psychological issues through acceptance and mindfulness respectively [74], thereby allowing for a gradual improvement in anxiety responses [75]. This strategy has proven to be highly effective in mitigating depressive symptoms, with the most pronounced improvement occurring after 3 months of therapy [76]. Other novel interventions such as the virtual reality exposure therapy (VRET) [77] and the progressive muscle relaxation (PMR) therapy [78] have also been shown to be efficacious in treating anxiety disorders and insomnia respectively $[79,80]$. In addition to psychiatric interventions, both psychosocial counselling and psychodynamic psychotherapy [81] are vital aspects of post-transplant donor care [82], especially for donors with poor recipient outcomes [28]. In the case of failed donation leading to recipient mortality, bereavement counselling services should be provided to improve donor outcome [83]. Besides donors of failed grafts, obese donors should also be closely monitored during counselling for issues pertaining to body image [48]. 
Peer mentoring programme. Potential donors should be paired with mentors as firsthand knowledge and personal encounters shared by previous donors have been reported to provide reassurance and emotional support [84]. This guidance and reassurance cannot be replicated by healthcare professionals who will only able to share facts rather than experiences due to the lack of first-hand encounters as donors [85].

Financial Support. The implementation of a comprehensive transplant program for donors is dependent on the availability of financial resources. Therefore, long-term financial support sourced from various stakeholders [86] in addition to health grants and donor contributions are vital for institutions to acquire. Private centres may also seek to establish contracts with governmental institutions to enhance their donor care program [48]. Ideally, financial coverage for donors should include transport costs for follow-up visits [35], medical complications of transplantation [87] and other out-of-pocket expenses [88]. Given that donation-related financial costs contribute to post-transplant anxiety and distress for donors, the establishment of a reliable financial safety net is warranted to ensure transplant centres can manage donors' socioeconomic concerns and overall wellbeing.

\subsection{Throughout Donation Process}

Multidisciplinary team. Transplant teams are involved throughout the transplantation process and comprise of transplant surgeons, nephrologists or hepatologists, radiologists, anaesthesiologists, psychologists, transplant coordinators and transplant nurses [89]. A recent study by Rodrigue et al. has concluded that emotional instability, anxiety about health and poorer sense of fulfilment in life are correlated with worse post-donation psychological outcomes [48]. The selection process of medically and psychosocially fit donors will be improved through the involvement of members with varying expertise [52], thereby increasing the chances of favourable mental outcomes. Donors' mental wellbeing can be further improved with shorter hospital stays and enhanced patient satisfaction as a result of more effective communication within the transplant teams [89]. The importance of the familiarity and support provided by transplant teams is evident from a study which showed that $70 \%$ of donors preferred their transplant coordinators to continue with the follow-up rather than their own family doctor [90]. Thus, improved follow-up compliance will allow better monitoring of the long-term welfare and mental health of donors [90].

Independent Living Donor Advocate (ILDA). All donors should be assigned an ILDA who can advocate for their rights and safety [35]. The ILDA should be adequately trained and remain uninvolved in recipient matters. The role of the ILDA involves ensuring that donors are educated about the transplantation process, including evaluation, surgical procedure and follow-up. The inclusion of an ILDA in the donation process enhances the quality of care of potential donors and facilitates ethical decision making during difficult circumstances [91]. Consequently, removing the need for self-advocacy may provide assurance and relieve donors of additional worries to facilitate successful post-transplant recovery [92] (Figure 2). 


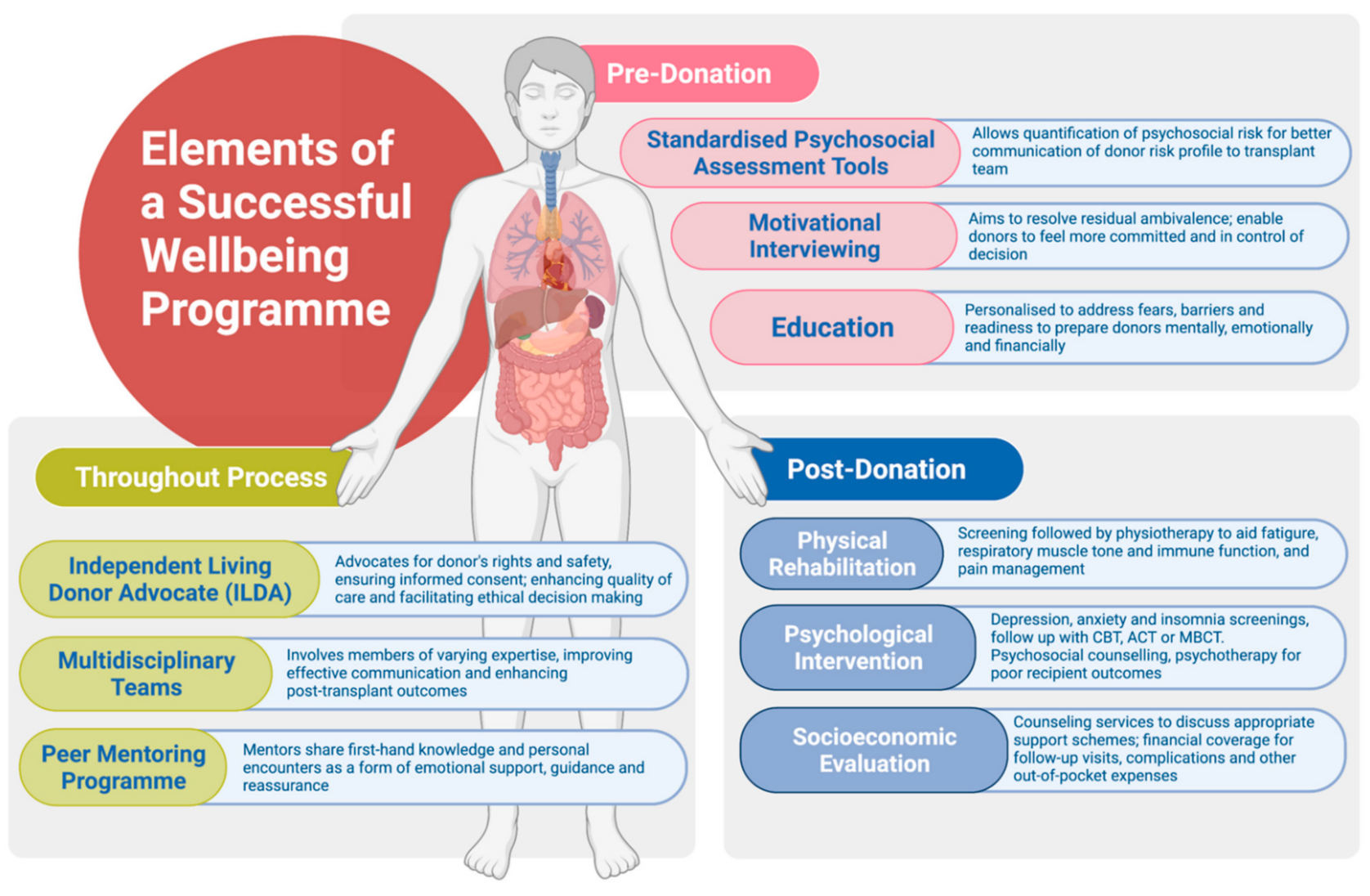

Figure 2. Elements of a Successful Wellbeing Programme.

\section{Gaps for Future Research}

Currently, the lack of literature on donor QOL fuels the need for further studies on this topic. One important aspect is the impact of recipient deaths on donors' mental health. The devastating effects on donors' physical recovery and psychological states [26] warrants further evaluations on the long-term psychological effects of recipient deaths on donors and validation of appropriate interventions for donors of failed grafts. Additionally, donors with pre-existing psychiatric disorders constitute another potentially vulnerable subpopulation. While some psychiatric patients qualify as potential donors, the lack of standardised guidelines on eligibility has led to considerable heterogeneity in donor evaluation [93], thus larger scale studies to validate donor criteria can be considered [94]. In other subgroups such as paediatric patients, organ transplantation is also considered the ideal treatment for children with end-stage liver or kidney disease $[95,96]$. Parent donors also face significant difficulties including financial constraints and caregiver burden which contribute to mental distress [97], highlighting the need for further improvements in the care of parent donors. While directed donations remain the most common source of living donor transplantations, an increasing acceptance of non-directed donations performed out of altruism $[98,99]$ has raised controversies surrounding the psychological stability of these donors [98]. This provides grounds for future research to understand "pure altruism" among organ donors and their motivations [98].

\section{Future Directions}

Living donors will become increasingly relevant for transplants as we head into the next decade. While medical issues of donors are the prime focus of current research, the psychosocial needs of donors remain largely unexplored. Current gaps in the literature prevent comprehensive care of donors after transplant and more studies are required especially from underrepresented regions. For instance, living donors remain the predominate source of organs in Asia and Middle East. However, the stigmatisation of mental disorders in 
these regions may misrepresent actual prevalence rates and warrants a careful approach of the topic. Importantly, a major gap of current literature lies in the systematic identification of high-risk donors after transplant and providing adequate support structure for these groups of patients, especially in the care of family donors with failed donations.

While the psychological stresses on donors post-transplant remain a true cause of concern, a subset of living donors report improved mental QOL after donation [100,101] benefitting from reduced caregiver burden, feelings of satisfaction due to active contribution to recipient treatment [102] and improved interpersonal relationships [34,102]. Interestingly, donors can also have positive perceptions of their surgical scars with some viewing their scars as a symbol of pride or awareness tool [103]. Nevertheless, the possible loss of anonymity proves problematic for living donors and remains an important issue to be addressed. Addressing these psychological impacts of transplantation is vital to optimize donor QOL and prevent the transplant community from losing advocates for living donation.

On the other hand, several protective factors predicting positive mental outcomes in living donors have been identified. For instance, the presence of social support has been shown to reduce ambivalence among donors [104] while donor resilience has been correlated with improved QOL post-transplant, due to reduced mental anxiety and a more favourable self-perception of well-being during evaluation [105]. This emphasises the importance of having pre-donation psychological assessment to improve mental outcomes of donors. Existing literature has also revealed that dispositional mindfulness and optimism may reduce symptoms of depression while promoting healthier cognition and emotional regulation in the wider population [106,107]. Similarly, spirituality and religion also serve as important sources of support to improve stress management [108]. These factors may reduce the emotional burden faced by living donors, although literature specific to the transplant donor population remains lacking. Thus, further studies are warranted to better understand the predictors of mental wellbeing among living donors.

To date, while many transplant societies have highlighted the importance of psychological assessment in donors, the pragmatic approach and lack of consensus on evaluation tools leaves much room for improvement. Here, we provide an overarching view of elements for consideration in transplant centres worldwide. Current research metrics also predominantly revolve around quantitative literature although there has been a call for an increase in qualitative literature in transplant [109]. While the perks of qualitative literature are beyond the scope of this review, several advantages include a deeper understanding of donor psychology, which sheds light on the factors contributing to reluctance to donate and poor psychosocial outcomes [109]. The utilization of these untapped tools could thus provide a better understanding of donors after transplant.

\section{Conclusions}

Our review has summarised the current landscape, donor impacts and society guidelines regarding living donor transplantations. The sacrifices of the donors are often untold and the current provision of support can be inadequate. The priceless sacrifices of donors should not be forgotten, and the care of their mental wellbeing should be of equal importance to the medical concerns throughout transplantation.

Author Contributions: Conceptualization: W.H.L. and C.H.N.; writing—original draft preparation: J.Z.K.T., X.-H.P., W.H.L. and C.H.N.; writing-review and editing: J.Z.K.T., X.-H.P., W.H.L. and C.H.N., P.W.L.T., N.W.W., A.W.C.K., A.V., E.X.-X.T. and M.D.M.; visualization: P.W.L.T.; supervision: C.H.N., N.W.W., A.W.C.K., A.V., E.X.-X.T. and M.D.M.; project administration: W.H.L. and C.H.N. All authors have read and agreed to the published version of the manuscript.

Funding: This research received no external funding.

Institutional Review Board Statement: Not applicable.

Informed Consent Statement: Not applicable. 
Data Availability Statement: All data is available in public depositories including Medline and Embase.

Acknowledgments: All authors have made substantial contribution to the following: (1) the conception and design of the study, or acquisition of data, or analysis and interpretation of data, (2) drafting the article or revising it critically for important intellectual content, (3) final approval of the version to be submitted. No writing assistance was obtained in the preparation of the manuscript. The manuscript, including related data, figures and tables has not been previously published and the manuscript is not under consideration elsewhere.

Conflicts of Interest: The authors declare no conflict of interest.

\section{References}

1. Merrill, J.P.; Harrison, J.H.; Murray, J.; Guild, W.R. Successful Homotransplantation of the Kidney in an Identical Twin. Trans. Am. Clin. Clim. Assoc. 1955, 67, 166-173.

2. Raia, S.; Nery, J.R.; Mies, S. Liver transplantation from live donors. Lancet 1989, 2, 497. [CrossRef]

3. Mahillo, B.; Carmona, M.; Alvarez, M.; Marco, J.; Nuñez, J.R.; López-Fraga, M.; Matesanz, R.; Domínguez-Gil, B. Worldwide distribution of solid organ transplantation and access of population to those practices. Transplantation 2018, 102, S71-S72. [CrossRef]

4. Abouna, G. Organ Shortage Crisis: Problems and Possible Solutions. Transplant. Proc. 2008, 40, 34-38. [CrossRef]

5. Shukla, A.; Vadeyar, H.; Rela, M.; Shah, S. Liver Transplantation: East versus West. J. Clin. Exp. Hepatol. $2013,3,243-253$. [CrossRef]

6. Akabayashi, A. Brain-Death and Organ Transplantation: The First Japanese Path. In Bioethics Across the Globe; Springer Science and Business Media LLC: Berlin, Germany, 2020; pp. 13-26.

7. Tong, A.; Chapman, J.R.; Kee, T.; Li, P.K.T.; Tsai, D.F.C.; Wong, G.; Craig, J.C. Perspectives of Transplant Professionals on the Values, Ethics, and Challenges of Living Kidney Donor Evaluation in Asia. Transplantation 2015, 99, 1386-1395. [CrossRef]

8. Lee, L.-Y.; Pham, T.A.; Melcher, M.L. Living Kidney Donation: Strategies to Increase the Donor Pool. Surg. Clin. N. Am. 2019, 99, 37-47. [CrossRef]

9. Russo, M.W.; Lapointe-Rudow, D.; Kinkhabwala, M.; Emond, J.; Brown, R.S. Impact of Adult Living Donor Liver Transplantation on Waiting Time Survival in Candidates Listed for Liver Transplantation. Arab. Archaeol. Epigr. 2004, 4, 427-431. [CrossRef]

10. Olthoff, K.M.; Smith, A.; Abecassis, M.; Baker, T.; Emond, J.C.; Berg, C.L.; Beil, C.A.; Burton, J.R.; Fisher, R.A.; Freise, C.E.; et al. Defining Long-term Outcomes with Living Donor Liver Transplantation in North America. Ann. Surg. 2015, 262, 465-475. [CrossRef]

11. Niemi, M.; Mandelbrot, D.A. The Outcomes of Living Kidney Donation from Medically Complex Donors: Implications for the Donor and the Recipient. Curr. Transplant. Rep. 2014, 1, 1-9. [CrossRef]

12. Levitsky, J. Does the Liver Provide Immunosuppressive Advantage? Clin. Liver Dis. 2019, 13, 180-183. [CrossRef]

13. Levitsky, J.; Feng, S. Tolerance in clinical liver transplantation. Hum. Immunol. 2018, 79, 283-287. [CrossRef]

14. Braun, H.J.; Ascher, N.L.; Roll, G.R.; Roberts, J.P. Biliary complications following living donor hepatectomy. Transplant. Rev. 2016, 30, 247-252. [CrossRef]

15. Lentine, K.L.; Lam, N.N.; Segev, D.L. Risks of living kidney donation: Current state of knowledge on outcomes important to donors. Clin. J. Am. Soc. Nephrol. 2019, 14, 597-608. [CrossRef]

16. Boyarsky, B.J.; Massie, A.B.; Alejo, J.L.; Van Arendonk, K.J.; Wildonger, S.; Garonzik-Wang, J.M.; Montgomery, R.A.; Deshpande, N.A.; Muzaale, A.D.; Segev, D.L. Experiences Obtaining Insurance After Live Kidney Donation. Arab. Archaeol. Epigr. 2014, 14, 2168-2172. [CrossRef]

17. The Lancet Gastroenterology \& Hepatology. Removing barriers to living organ donation. Lancet Gastroenterol. Hepatol. 2021, 6, 335. [CrossRef]

18. OPTN/SRTR 2019 Annual Data Report: Kidney. 2019. Available online: https://srtr.transplant.hrsa.gov/annual_reports/2019 /Kidney.aspx (accessed on 6 May 2021).

19. OPTN/SRTR 2019 Annual Data Report: Liver. 2019. Available online: https://srtr.transplant.hrsa.gov/annual_reports/2019 /Liver.aspx (accessed on 6 May 2021).

20. Abu-Gazala, S.; Olthoff, K.M. Current Status of Living Donor Liver Transplantation in the United States. Annu. Rev. Med. 2019, 70, 225-238. [CrossRef]

21. 2020 Organ Procurement Transplantation Network. Available online: https:/ / optn.transplant.hrsa.gov/data/view-data-reports / build-advanced/ (accessed on 6 May 2021).

22. Ghobrial, R.M.; Freise, C.E.; Trotter, J.F.; Tong, L.; Ojo, A.O.; Fair, J.H.; Fisher, R.A.; Emond, J.C.; Koffron, A.J.; Pruett, T.L.; et al. Donor Morbidity after Living Donation for Liver Transplantation. Gastroenterol 2008, 135, 468-476. [CrossRef]

23. Sommerer, C.; Morath, C.; Andrassy, J.; Zeier, M. The long-term consequences of living-related or unrelated kidney donation. Nephrol. Dial. Transplant. 2004, 19, iv45-iv47. [CrossRef]

24. Butt, Z.; DiMartini, A.F.; Liu, Q.; Simpson, M.A.; Smith, A.R.; Zee, J.; Gillespie, B.W.; Holtzman, S.; Ladner, D.; Olthoff, K.; et al. Fatigue, Pain, and Other Physical Symptoms of Living Liver Donors in the Adult-to-Adult Living Donor Liver Transplantation Cohort Study. Liver Transplant. 2018, 24, 1221-1232. [CrossRef] 
25. Chien, C.H.; Wang, H.-H.; Chiang, Y.-J.; Chu, S.-H.; Liu, H.-E.; Liu, K.-L. Quality of Life After Laparoscopic Donor Nephrectomy. Transplant. Proc. 2010, 42, 696-698. [CrossRef]

26. Ladner, D.P.; Dew, M.A.; Forney, S.; Gillespie, B.W.; Brown, R.S.; Merion, R.M.; Freise, C.E.; Hayashi, P.H.; Hong, J.C.; Ashworth, A.; et al. Long-term quality of life after liver donation in the adult to adult living donor liver transplantation cohort study (A2ALL). J. Hepatol. 2015, 62, 346-353. [CrossRef]

27. Wee, I.J.; Syn, N.; Lee, L.S.; Tan, S.S.; Chiow, A.K. A systematic review and meta-analysis on the quality of life after hepatic resection. HPB 2020, 22, 177-186. [CrossRef]

28. Butt, Z.; Dew, M.A.; Liu, Q.; Simpson, M.A.; Smith, A.R.; Zee, J.; Gillespie, B.W.; Abbey, S.E.; Ladner, D.P.; Weinrieb, R.; et al. Psychological Outcomes of Living Liver Donors from a Multicenter Prospective Study: Results From the Adult-to-Adult Living Donor Liver Transplantation Cohort Study2 (A2ALL-2). Arab. Archaeol. Epigr. 2016, 17, 1267-1277. [CrossRef]

29. Walter, M.; Papachristou, C.; Pascher, A.; Danzer, G.; Neuhaus, P.; Klapp, B.F.; Frommer, J. Impaired psychosocial outcome of donors after living donor liver transplantation: A qualitative case study. Clin. Transplant. 2006, 20, 410-415. [CrossRef]

30. Shi, Y.; Liu, C.; Zhang, H.; Huang, Y.; Sun, M.; Wang, W.; Shang, S. Changes in the quality of life of living liver donors: A meta-analysis. Int. J. Nurs. Stud. 2020, 109, 103586. [CrossRef]

31. Watson, J.M.; Behnke, M.K.; Fabrizio, M.D.; McCune, T.R. Recipient graft failure or death impact on living kidney donor quality of life based on the living organ donor network database. J. Endourol. 2013, 27, 1525-1529. [CrossRef]

32. Lentine, K.L.; Schnitzler, M.A.; Xiao, H.; Axelrod, D.; Davis, C.L.; McCabe, M.; Brennan, D.C.; Leander, S.; Garg, A.X.; Waterman, A. Depression diagnoses after living kidney donation: Linking U.S. Registry data and administrative claims. Transplantation 2012, 94, 77-83. [CrossRef]

33. Massey, E.K.; Timmerman, L.; Ismail, S.Y.; Duerinckx, N.; Lopes, A.; Maple, H.; Mega, I.; Papachristou, C.; Dobbels, F.; ELPAT Psychosocial Care for Living Donors and Recipients Working Group. The ELPAT living organ donor Psychosocial Assessment Tool (EPAT): From 'what' to 'how' of psychosocial screening-A pilot study. Transpl. Int. 2018, 31, 56-70. [CrossRef]

34. DiMartini, A.; Dew, M.A.; Liu, Q.; Simpson, M.A.; Ladner, D.P.; Smith, A.; Zee, J.; Abbey, S.; Gillespie, B.W.; Weinrieb, R.; et al. Social and Financial Outcomes of Living Liver Donation: A Prospective Investigation Within the Adult-to-Adult Living Donor Liver Transplantation Cohort Study 2 (A2ALL-2). Arab. Archaeol. Epigr. 2017, 17, 1081-1096. [CrossRef]

35. Organ Procurement and Transplantation Network. Organ Procurement and Transplantation Network (OPTN) Policies; United Network for Organ Sharing: Richmond, VA, USA, 1984.

36. British Transplantation Society. Living Donor Liver Transplantation; British Transplantation Society: Birmingham, UK, 2015.

37. British Transplantation Society. Guidelines for Living Donor Kidney Transplantation, 4th ed.; British Transplantation Society: Birmingham, UK, 2018.

38. Lentine, K.L.; Kasiske, B.L.; Levey, A.S.; Adams, P.L.; Alberú, J.; Bakr, M.A.; Gallon, L.; Garvey, C.A.; Guleria, S.; Li, P.K.-T.; et al. KDIGO Clinical Practice Guideline on the Evaluation and Care of Living Kidney Donors. Transplant 2017, 101, S7-S105. [CrossRef] [PubMed]

39. Medical Development Division Malaysia. National Organ, Tissue and Cell Transplantation Policy; Malaysian Ministry of Health: Putrajaya, Malaysia, 2007.

40. Regulation on Human Organ Transplant. Renti Qiguan Yizhi Tiaoli; The Central People's Government of the People's Republic of China: Beijing, China, 2011.

41. Kute, V.B.; Agarwal, S.K.; Sahay, M.; Kumar, A.; Rathi, M.; Prasad, N.; Sharma, R.K.; Gupta, K.L.; Shroff, S.; Saxena, S.K.; et al. Kidney-paired donation to increase living donor kidney transplantation in India: Guidelines of Indian Society of Organ Transplantation-2017. Indian J. Nephrol. 2018, 28, 1-9. [CrossRef] [PubMed]

42. Japanese Liver Transplantation Society. Guidelines for Liver Donor Surgery. Available online: http://jlts.umin.ac.jp/history/ donor.html (accessed on 7 May 2021).

43. Malaysian Medical Council. Organ Transplantation, Guideline of the Malaysian Medical Council; Malaysian Ministry of Health: Putrajaya, Malaysia, 2006.

44. Ergene, T.; Karadibak, D.; Polat, K.Y. Fatigue and Physiotherapy in Liver Transplant Recipients Fatigue and Physiotherapy. Clin. Exp. Health Sci. 2019, 9, 278-282. [CrossRef]

45. Pang, A.; Lingham, S.; Zhao, W.; LeDuc, S.; Räkel, A.; Sapir-Pichhadze, R.; Mathur, S.; Janaudis-Ferreira, T. Physician Practice Patterns and Barriers to Counselling on Physical Activity in Solid Organ Transplant Recipients. Ann. Transplant. 2018, 23, 345-359. [CrossRef]

46. National Institute of Diabetes and Digestive and Kidney Diseases. Adult Living Donor Liver Transplantation Studies (A2ALL); United States National Institutes of Health: Bethesda, MD, USA, 2003.

47. Arbor Research Collaborative for Health. Adult-to-Adult Living Donor Transplant Cohort Study (A2ALL-2); United States National Institutes of Health: Bethesda, MD, USA, 2012.

48. Rodrigue, J.R.; Schold, J.D.; Morrissey, P.; Whiting, P.; Vella, J.; Kayler, L.K.; Katz, D.; Jones, J.; Kaplan, B.; Fleishman, A.; et al. Mood, body image, fear of kidney failure, life satisfaction, and decisional stability following living kidney donation: Findings from the KDOC study. Am. J. Transplant. 2018, 18, 1397-1407. [CrossRef]

49. Chen, J.; Bhattacharya, S.; Sirota, M.; Laiudompitak, S.; Schaefer, H.; Thomson, E.; Wiser, J.; Sarwal, M.M.; Butte, A.J. Assessment of Postdonation Outcomes in US Living Kidney Donors Using Publicly Available Data Sets. JAMA Netw. Open 2019, 2 , e191851. [CrossRef] 
50. Faeder, S.; Moschenross, D.; Rosenberger, E.; Dew, M.A.; DiMartini, A. Psychiatric aspects of organ transplantation and donation. Curr. Opin. Psychiatry 2015, 28, 357-364. [CrossRef]

51. Waterman, A.D.; Robbins, M.L.; Paiva, A.L.; Peipert, J.D.; Kynard-Amerson, C.S.; Goalby, C.J.; Davis, L.A.; Thein, J.L.; Schenk, E.A.; Baldwin, K.A.; et al. Your Path to Transplant: A randomized controlled trial of a tailored computer education intervention to increase living donor kidney transplant. BMC Nephrol. 2014, 15, 166. [CrossRef]

52. Moore, D.R.; Serur, D.; Rudow, D.L.; Rodrigue, J.R.; Hays, R.; Cooper, M. Living Donor Kidney Transplantation: Improving Efficiencies in Live Kidney Donor Evaluation-Recommendations from a Consensus Conference. Clin. J. Am. Soc. Nephrol. 2015, 10, 1678-1686. [CrossRef]

53. Dageforde, L.A.; Petersen, A.W.; Feurer, I.D.; Cavanaugh, K.L.; Harms, K.A.; Ehrenfeld, J.M.; Moore, D.E. Health Literacy of Living Kidney Donors and Kidney Transplant Recipients. Transplant 2014, 98, 88-93. [CrossRef]

54. Dew, M.A.; DiMartini, A.F.; Dabbs, A.J.D.; Zuckoff, A.; Tan, H.P.; McNulty, M.L.; Switzer, G.E.; Fox, K.R.; Greenhouse, J.B.; Humar, A. Preventive Intervention for Living Donor Psychosocial Outcomes: Feasibility and Efficacy in a Randomized Controlled Trial. Arab. Archaeol. Epigr. 2013, 13, 2672-2684. [CrossRef]

55. Zuckoff, A.; Dew, M.A. Research on MI in Equipoise: The Case of Living Organ Donation. Motiv. Interviewing Train. Res. Implement. Pract. 2012, 1, 39-41. [CrossRef]

56. Holscher, C.M.; Leanza, J.; Thomas, A.G.; Waldram, M.M.; Haugen, C.E.; Jackson, K.R.; Bae, S.; Massie, A.B.; Segev, D.L. Anxiety, depression, and regret of donation in living kidney donors. BMC Nephrol. 2018, 19, 1-7. [CrossRef]

57. Glaser, B.; Suter, E. Interprofessional collaboration and integration as experienced by social workers in health care. Soc. Work Health Care 2016, 55, 395-408. [CrossRef]

58. Barr, M.L.; Belghiti, J.; Villamil, F.G.; Pomfret, E.A.; Sutherland, D.S.; Gruessner, R.W.; Langnas, A.N.; Delmonico, F.L. A Report of the Vancouver Forum on the Care of the Live Organ Donor: Lung, Liver, Pancreas, and Intestine Data and Medical Guidelines. Transplant 2006, 81, 1373-1385. [CrossRef]

59. Takada, Y.; Suzukamo, Y.; Oike, F.; Egawa, H.; Morita, S.; Fukuhara, S.; Uemoto, S.; Tanaka, K. Long-term quality of life of donors after living donor liver transplantation. Liver Transpl. 2012, 18, 1343-1352. [CrossRef]

60. Bossola, M.; Pepe, G.; Vulpio, C. Fatigue in kidney transplant recipients. Clin. Transplant. 2016, 30, 1387-1393. [CrossRef]

61. Katz, N. The Impact of Pain Management on Quality of Life. J. Pain Symptom Manag. 2002, 24, S38-S47. [CrossRef]

62. Tang, N.K.Y.; Crane, C. Suicidality in chronic pain: A review of the prevalence, risk factors and psychological links. Psychol. Med. 2006, 36, 575-586. [CrossRef]

63. Onofre, T.; Junior, J.F.F.; Amorim, C.F.; Minamoto, S.T.; Paisani, D.D.M.; Chiavegato, L.D. Impact of an early physiotherapy program after kidney transplant during hospital stay: A randomized controlled trial. Braz. J. Nephrol. 2017, 39, 424-432. [CrossRef]

64. Dewe, G.; Steyaert, A.; De Kock, M.; Lois, F.; Reding, R.; Forget, P. Pain management in living related adult donor hepatectomy: Feasibility of an evidence-based protocol in 100 consecutive donors. BMC Res. Notes 2018, 11, 834. [CrossRef] [PubMed]

65. Rodrigue, J.R.; Fleishman, A.; Schold, J.D.; Morrissey, P.; Whiting, J.; Vella, J.; Kayler, L.K.; Katz, D.A.; Jones, J.; Kaplan, B.; et al. Patterns and predictors of fatigue following living donor nephrectomy: Findings from the KDOC Study. Am. J. Transplant. 2020, 20, 181-189. [CrossRef] [PubMed]

66. Jowsey, S.G.; Jacobs, C.; Gross, C.R.; Hong, B.A.; Messersmith, E.E.; Gillespie, B.W.; Beebe, T.J.; Kew, C.; Matas, A.J.; Yusen, R.D.; et al. Emotional Well-Being of Living Kidney Donors: Findings from the RELIVE Study. Arab. Archaeol. Epigr. 2014, 14, 2535-2544. [CrossRef] [PubMed]

67. Jenkinson, C.; Coulter, A.; Wright, L. Short form 36 (SF36) health survey questionnaire: Normative data for adults of working age. BMJ 1993, 306, 1437-1440. [CrossRef]

68. Kroenke, K.; Spitzer, R.L.; Williams, J.B. The PHQ-9: Validity of a brief depression severity measure. J. Gen. Intern. Med. 2001, 16, 606-613. [CrossRef]

69. Johnson, S.U.; Ulvenes, P.G.; Øktedalen, T.; Hoffart, A. Psychometric Properties of the General Anxiety Disorder 7-Item (GAD-7) Scale in a Heterogeneous Psychiatric Sample. Front. Psychol. 2019, 10, 1713. [CrossRef]

70. Backhaus, J.; Junghanns, K.; Broocks, A.; Riemann, D.; Hohagen, F. Test-retest reliability and validity of the Pittsburgh Sleep Quality Index in primary insomnia. J. Psychosom. Res. 2002, 53, 737-740. [CrossRef]

71. Beck, A.T. Cognitive therapy: Nature and relation to behavior therapy. Behav. Ther. 1970, 1, 184-200. [CrossRef]

72. Hofmann, S.G.; Asnaani, A.; Vonk, I.J.J.; Sawyer, A.T.; Fang, A. The Efficacy of Cognitive Behavioral Therapy: A Review of Meta-analyses. Cogn. Ther. Res. 2012, 36, 427-440. [CrossRef]

73. Foroushani, P.S.; Schneider, J.; Assareh, N. Meta-review of the effectiveness of computerised CBT in treating depression. BMC Psychiatry 2011, 11, 131. [CrossRef]

74. Hayes, S.C.; Luoma, J.B.; Bond, F.W.; Masuda, A.; Lillis, J. Acceptance and Commitment Therapy: Model, processes and outcomes. Behav. Res. Ther. 2006, 44, 1-25. [CrossRef]

75. Twohig, M.P.; Levin, M.E. Acceptance and Commitment Therapy as a Treatment for Anxiety and Depression: A Review. Psychiatr. Clin. N. Am. 2017, 40, 751-770. [CrossRef]

76. Bai, Z.; Luo, S.; Zhang, L.; Wu, S.; Chi, I. Acceptance and Commitment Therapy (ACT) to reduce depression: A systematic review and meta-analysis. J. Affect. Disord. 2020, 260, 728-737. [CrossRef]

77. Krijn, M.; Emmelkamp, P.; Biemond, R.; Ligny, C.D.W.D.; Schuemie, M.J.; van der Mast, C.A. Treatment of acrophobia in virtual reality: The role of immersion and presence. Behav. Res. Ther. 2004, 42, 229-239. [CrossRef] 
78. Spielman, A.J.; Caruso, L.S.; Glovinsky, P.B. A Behavioral Perspective on Insomnia Treatment. Psychiatr. Clin. N. Am. 1987, 10, 541-553. [CrossRef]

79. Powers, M.B.; Emmelkamp, P. Virtual reality exposure therapy for anxiety disorders: A meta-analysis. J. Anxiety Disord. 2008, 22, 561-569. [CrossRef]

80. Morin, C.M.; Hauri, P.J.; Espie, C.A.; Spielman, A.J.; Buysse, D.J.; Bootzin, R.R. Nonpharmacologic Treatment of Chronic Insomnia. Sleep 1999, 22, 1134-1156. [CrossRef]

81. Leichsenring, F.; Leibing, E. Psychodynamic psychotherapy: A systematic review of techniques, indications and empirical evidence. Psychol. Psychother. Theory Res. Pract. 2007, 80, 217-228. [CrossRef]

82. Goetzmann, L.; Wagner-Huber, R.; Klaghofer, R.; Muellhaupt, B.; Clavien, P.; Buddeberg, C.; Scheuer, E. Waiting for a Liver Transplant: Psychosocial Well-Being, Spirituality, and Need for Counselling. Transplant. Proc. 2006, 38, 2931-2936. [CrossRef]

83. Gallagher, M.; Tracey, A.; Millar, R. Ex-clients' evaluation of bereavement counselling in a voluntary sector agency. Psychol. Psychother. Theory Res. Pract. 2005, 78, 59-76. [CrossRef]

84. University of Michigan Health Michigan Medicine. Kidney Transplant Peer Mentor Program; University of Medicine and Health Sciences: Ann Arbor, MI, USA, 2020.

85. American Transplant Foundation. Mentorship Testimonials; American Transplant Foundation: Denver, CO, USA, 2019.

86. Fraser, R.T.; McMahon, B.T.; Wiggins, A.; Clift, A.; Hunter-Banks, S. Considerations in developing a specialized epilepsy employment program: A sponsor's playbook. Epilepsy Behav. 2020, 102, 106698. [CrossRef] [PubMed]

87. Tietjen, A.; Hays, R.; McNatt, G.; Howey, R.; Lebron-Banks, U.; Thomas, C.; Lentine, K.L. Billing for Living Kidney Donor Care: Balancing Cost Recovery, Regulatory Compliance, and Minimized Donor Burden. Curr. Transplant. Rep. 2019, 6, 155-166. [CrossRef] [PubMed]

88. Jacobs, C.; Thomas, C. Financial considerations in living organ donation. Prog. Transplant. 2003, 13, 130-136. [CrossRef] [PubMed]

89. Fonouni, H.; Golriz, M.; Mehrabi, A.; Oweira, H.; Schmied, B.; Müller, S.; Jarahian, P.; Rad, M.T.; Esmaeilzadeh, M.; Tönshoff, B.; et al. The Role of an Interdisciplinary Transplant Team on Living Donation Kidney Transplantation Program. Transplant. Proc. 2010, 42, 137-140. [CrossRef]

90. Lumsdaine, J.; Wigmore, S.; Wooton, D.; Stewart, C.; Akyol, M.; Forsythe, J. Establishing a transplant coordinator-led living kidney donor follow-up clinic. Prog. Transplant. 2003, 13, 138-141. [CrossRef]

91. Rudow, D.L.; Brown, R.S., Jr. Role of the independent donor advocacy team in ethical decision making. Prog. Transplant. 2005, 15, 298-302. [CrossRef]

92. Killian, A.C.; Reed, R.D.; Carter, A.; McLeod, M.C.; Shelton, B.A.; Kumar, V.; Qu, H.; MacLennan, P.A.; Orandi, B.J.; Cannon, R.M.; et al. Self-advocacy is associated with lower likelihood of living donor kidney transplantation. Am. J. Surg. 2021, $222,36-41$. [CrossRef]

93. Cahn-Fuller, K.L.; Parent, B. Transplant eligibility for patients with affective and psychotic disorders: A review of practices and a call for justice. BMC Med. Ethics 2017, 18, 72. [CrossRef]

94. Rowley, A.A.; Hong, B.A.; Martin, S.; Jones, L.; Vijayan, A.; Shenoy, S.; Jendrisak, M. Psychiatric disorders: Are they an absolute contraindication to living donation? Prog. Transplant. 2009, 19, 128-131. [CrossRef]

95. Pham, Y.H.; Miloh, T. Liver Transplantation in Children. Clin. Liver Dis. 2018, 22, 807-821. [CrossRef]

96. Saeed, B. Pediatric renal transplantation. Int. J. Organ. Transplant. Med. 2012, 3, 62-73.

97. Kärrfelt, H.M.E.; Berg, U.B.; Lindblad, F.I.E. Renal transplantation in children: Psychological and donation-related aspects from the parental perspective. Pediatr. Transplant. 2000, 4, 305-312. [CrossRef]

98. Organ Procurement and Transplantation Network (OPTN) Living Non-Directed Organ Donation; United Network for Organ Sharing: Richmond, VA, USA, 2015.

99. Moorlock, G.; Ives, J.; Draper, H. Altruism in organ donation: An unnecessary requirement? Table 1. J. Med. Ethics 2013, 40, 134-138. [CrossRef]

100. Schulz, K.-H.; Kroencke, S.; Beckmann, M.; Nadalin, S.; Paul, A.; Fischer, L.; Nashan, B.; Senf, W.; Erim, Y. Mental and physical quality of life in actual living liver donors versus potential living liver donors: A prospective, controlled, multicenter study. Liver Transplant. 2009, 15, 1676-1687. [CrossRef]

101. Burra, P.; De Bona, M. Quality of life following organ transplantation. Transpl. Int. 2007, 20, 397-409. [CrossRef]

102. Papachristou, C.; Walter, M.; Schmid, G.; Frommer, J.; Klapp, B. Living donor liver transplantation and its effect on the donor-recipient relationship-a qualitative interview study with donors. Clin. Transplant. 2009, 23, 382-391. [CrossRef]

103. Krause, S.; Pritlove, C.; Abbey, S.; Jung, J. The Meaning Behind the Scar: Anonymous Live Liver Donors' Perceptions of Their Surgical Scars. Transplant 2021, 105, 1039-1043. [CrossRef]

104. Lai, Y.-C.; Lee, W.-C.; Juang, Y.-Y.; Yen, L.-L.; Weng, L.-C.; Chou, H.F. Effect of social support and donation-related concerns on ambivalence of living liver donor candidates. Liver Transplant. 2014, 20, 1365-1371. [CrossRef]

105. Erim, Y.; Kahraman, Y.; Vitinius, F.; Beckmann, M.; Kroncke, S.; Witzke, O. Resilience and quality of life in 161 living kidney donors before nephrectomy and in the aftermath of donation: A naturalistic single center study. BMC Nephrol. 2015, 16, 164. [CrossRef]

106. Tomlinson, E.R.; Yousaf, O.; Vittersø, A.D.; Jones, L. Dispositional Mindfulness and Psychological Health: A Systematic Review. Mindfulness 2018, 9, 23-43. [CrossRef] 
107. Conversano, C.; Rotondo, A.; Lensi, E.; Della Vista, O.; Arpone, F.; Reda, M.A. Optimism and Its Impact on Mental and Physical Well-Being. Clin. Pract. Epidemiol. Ment. Health 2010, 6, 25-29. [CrossRef]

108. Koenig, H.G. Research on Religion, Spirituality, and Mental Health: A Review. Can. J. Psychiatry 2009, 54, 283-291. [CrossRef]

109. Tong, A.; Chapman, J.R.; Israni, A.; Gordon, E.J.; Craig, J.C. Qualitative research in organ transplantation: Recent contributions to clinical care and policy. Am. J. Transplant. 2013, 13, 1390-1399. [CrossRef] [PubMed] 